\title{
NÂNG CAO NHẬN THÚ̉C VỀ TIÊU DÙNG BỀN VŨ̉NG CỦA HỌC SINH TRUNG HỌC PHỔ THÔNG KHU VỰC NỘI THÀNH THÀNH PHỐ HỒ CHÍ MINH
}

\author{
Đặng Thị Thanh Lêe ${ }^{1}$ Nguyễn Kỳ Phùng ${ }^{2}$, Tô Thị Hiền ${ }^{1}$, Nguyễn Thị Thu Hiền ${ }^{3}$, \\ Huỳnh Ngọc Thúy An ${ }^{3}$, Võ Vân $\mathrm{Anh}^{3}$
}

Tóm tắt: Chưong trình truyền thông nâng cao nhận thức về tiêu dùng bền vũng cho học sinh trung hoc phổ thông được triển khai tại 6 trường trung học phổ thông khu vưc nội thành thành phố Hồ Chi Minh, nội dung được chia thành 4 buổi tập huấn với các chủ đề truyền thông bao gồm kiến thức co bản về tiêu dùng bền vĩng, dấu chân sinh thái, công cu tiêu dùng bền vĩng và hành động tiêu dùng bền vũng trong các lĩnh vực năng lượng, phương tiện, hàng tiêu dùng - mua sắm, thực phẩm, thời gian rãnh - được chuyển tải qua các kênh tập huấn, poster, brochure, sổ tay, tài liệu. Theo đó, chưong trình truyền thông đã được tổ chức và đạt được nhũng phản hồi tích cực, kết quả khảo sát 266 học sinh trung hoc phổ thông trước và sau chuơng trình cho thấy, 87,97\% học sinh đã nắm được những kiến thức nền tảng của tiêu dùng bền vũng, nhận thức và thái độ của hầu hết các em học sinh về tiêu dùng bền vĩng đều khá tốt, 98,12\% học sinh đều mong muốn tiêu dùng bền vũng và tìm hiểu thêm nhiều kiến thức về tiêu dùng bền vũng hơn nữa, hành vi tiêu dùng của các em học sinh đã có nhũng buớc chuyển dịch rõ nét sau chuơng trình, 85,72\% các em hoc sinh sẽ thuờng xuyên thực hiện các hành vi tiêu dùng thân thiện trong cuộc sống hằng ngày.

Từ khóa: Tiêu dùng bền vũng, chuơng trình truyền thông, hành vi tiêu dùng bền vĩng, học sinh trung hoc phổ thông.

Ban Biên tập nhận bài: 11/12/2019 Ngày phản biên xong: 12/12/2019 Ngày đăng bài: 20/12/2019

\section{Mở đầu}

Sự suy thoái môi trường mà nguyên nhân chính là dân số, sự tiêu dùng và công nghệ đã đạt đến mức cần phải hành động ngay lập tức. Nghèo đói vẫn còn tràn lan ở nhiều nơi trên thế giới. Tình hình an ninh vẫn không ổn định do những trận chiến vẫn tiếp tục diễn ra để tiếp cận với nguồn tài nguyên thiên nhiên và nguồn lực con người. Việc hội nhập và gắn kết trong xã hội đa văn hóa ngày càng phức tạp do nhiều người thiếu sự tiếp cận với những nhu cầu cơ bản. Song song đó những khó khăn do khủng hoảng và phụ thuộc vào tài chính tăng lên, các vấn đề sức khỏe thể chất và tinh thần liên quan đến những lựa chọn lối sống trở thành những lo ngại toàn cầu [15].
Những lựa chọn tiêu dùng là những quyết định mạnh mẽ mà chúng ta thực hiện trong cuộc sống hàng ngày, nhưng có lẽ chúng ta không nhìn thấy được những hậu quả và tác động của chúng. Những lựa chọn tiêu dùng định hình thị trường và mô hình sản xuất. Chúng có những tác động to lớn đến nguồn tài nguyên thiên nhiên và những hệ sinh thái cũng như cộng đồng toàn cầu - đóng góp vào những vấn đề biến đổi khí hậu và nhân quyền. Bên cạnh đó, thông qua những lựa chọn mua sắm, người tiêu dùng cũng gửi những thông điệp đến các nhà ra quyết định trong chính phủ, các ngành công nghiệp và các công ty [15].

TP. Hồ Chí Minh là trung tâm về thương mại,

${ }^{1}$ Đại học Khoa họ Tụ nhiên - Đại học Quốc gia thành phố Hồ Chí Minh

${ }^{2}$ Viện khoa hoc và công nghệ tính toán

${ }^{3}$ Đại học Tài nguyên và Môi trường Thành phố Hồ Chí Minh

Email:dttle@hcmus.edu.vn;kyphungng@gmail.com 
khoa học - công nghệ, tài chính, đào tạo nguồn nhân lực,...của cả nước. Quá trình đô thị hóa tại TP. HCM đang diễn ra nhanh chóng góp phần làm gia tăng khoảng cách giàu nghèo và sức ép với tài nguyên thiên nhiên và môi trường, song song đó là sự chênh lệch về bối cảnh xã hội, cơ sở hạ tầng và nhận thức cũng ngày một gia tăng. Cùng với định hướng phát triển đô thị hướng tới phát triển bền vững thích ứng với biến đổi khí hậu, TP.HCM đưa ra những chính sách thích ứng với kinh tế tuần hoàn như đặt ra hàng loạt mục tiêu như đến 2020 giảm 60\% lượng túi nilon khó phân hủy tại siêu thị, trung tâm thương mại và $50 \%$ tại chợ truyền thống; năng lượng tái tại và năng lượng mới sẽ đạt 1,7\% tổng công suất năng lượng, thực hiện Chỉ thị số 19/CT-TTg ngày 19/7/2019 của Thủ tướng Chính phủ về các giải pháp thúc đẩy tăng trưởng và phát triển bền vững Vùng kinh tế trọng điểm phía Nam [11]. Năm 2017, Ủy ban nhân dân Thành phố đã ban hành kế hoạch triển khai Chiến lược quốc gia về Tăng trưởng xanh, theo đó Chiến lược Tăng trưởng xanh trên địa bàn thành phố nhằm mục tiêu cốt lõi là chuyển dịch từ nền kinh tế nâu sang kinh tế xanh, củng cố hành vi tiêu dùng xanh trong cộng đồng người dân [12]. Để thực hiện sự chuyển dịch này phải bắt đầu từ một sự dịch chuyển tư duy căn bản để mọi người, mọi công dân ở mọi ngành nghề hiểu được tính nghiêm trọng và sự cần thiết của sự dịch chuyển. Điều này kêu gọi một sự nỗ lực chung để huy động những nguồn lực giáo dục, để đào tạo một thế hệ công dân mới, doanh nhân, quan chức và xã hội dân sự nắm hiểu được những nguyên lý của nền Kinh tế Xanh, để ứng phó với những thách thức đang xen mà chúng ta đang phải đối mặt.

Các nghiên cứu về đặc điểm tâm lý lứa tuổi thanh niên (học sinh trung học phổ thông) và một số thực trạng xã hội có liên quan đến lứa tuổi này cho thấy đây là giai đoạn chuyển tiếp giữa trẻ em và người lớn, bên cạnh những thay đổi về thể chất, tâm lý thì vai trò trong xã hội của các em cũng có những thay đổi cơ bản. Có thế thấy đây là độ tuổi thích hợp để các em hình thành những thói quen mới tích cực, kịp thời sửa đổi những thói quen cũ. Đồng thời dễ dàng để các em lan tỏa những kiến thức bổ ích đến gia đình, người thân của mình, chính vì thế việc cung cấp cho các em các kiến thức về môi trường nói chung và tiêu dùng bền vững nói riêng sẽ có những tác động cụ thể.

Hiện nay trên thế giới nhiều hoạt động nhằm nâng cao nhận thức của người tiêu dùng được triển khai thực hiện như "Chiến dịch quốc gia thúc đẩy việc thu năng lượng Mặt trời” được xúc tiến bởi Hiệp hội quản lý môi trường Đức và được thực hiện tại 16 bang của Cộng Hòa Liên Bang Đức, chiến dịch đã mạng lại sự quan tâm chung đến điện mặt trời và sự chấp nhận của người tiêu dùng với các thiết bị năng lượng mặt trời. "Dự án DAWN về năng lực và môi trường" với mục đích là làm cho mọi người nhận thức được về lợi ích của việc tiết kiệm năng lượng trong lối sống thường nhật, đối tượng chính của dự án này là thầy cô giáo và sinh viên trong hơn 600 trường trên toàn Thái Lan [17].

Tại Việt Nam, trong những năm qua, Việt Nam đã triển khai một số chương trình truyền thông liên quan đến vấn đề tiết kiệm năng lượng và tiêu dùng bền vững điển hình là chương trình Sống xanh Việt Nam (Get Green Viet Nam) đây là dự án thúc đẩy tiêu dùng bền vững được triển khai tại sáu đô thị lớn là Hà Nội, Thành phố Hồ Chí Minh, Quảng Ninh, Đà Nẵng, Nha Trang và Cần Thơ do chương trình SWITCH-Asia của Liên minh châu Âu tài trợ, Đại học Công nghệ Delft (Hà Lan), Trung tâm Sản xuất sạch hơn Việt Nam và Viện Công nghệ châu Á tại Việt Nam phối hợp thực hiện. Mục tiêu của dự án là thành lập hàng trăm câu lạc bộ tiêu dùng bền vững và xây dựng mạng lưới 1.000 người tiêu dùng thông thái để phổ biến phong cách sống và làm việc bền vững trong cộng đồng [13].

Bên cạnh đó, nhận thức được tầm quan trọng 
của công tác giáo dục môi trường đối với thế hệ trẻ tương lai của đất nước, trong những năm vừa qua, các hoạt động giáo dục môi trường dành cho lứa tuổi học sinh được tích cực đẩy mạnh. Từ đó, tạo ra sự đổi mới trong nhận thức của các em học sinh về môi trường. Chương trình giáo dục truyền thông trong trường học giai đoạn 20162020 do Sở Tài nguyên và Môi trường và Sở Giáo dục và Đào tạo thống nhất ban hành Kế hoạch liên Sở về việc phối hợp triển khai các hoạt động giáo dục và truyền thông môi trường nhằm phát huy và nâng cao hiệu quả các hoạt động giáo dục và truyền thông môi trường trong trường học trên địa bàn TP.HCM, với mục đích nâng cao nhận thức, từng bước thay đổi hành vi và hình thành thói quen bảo vệ môi trường cho học sinh, bên cạnh đó nhân rộng mô hình trường học xanh - sạch - đẹp, thực hiện các giải pháp $3 T$ (tiết giảm, tái sử dụng, tái chế) và phân loại chất thải tại nguồn, tham gia bảo vệ môi trường.
Mục tiêu của nghiên cứu là triển khai Chương trình "Truyền thông nâng cao nhận thức về tiêu dùng bền vững cho học sinh Trung học phổ thông khu vực nội thành thành phố Hồ Chí Minh" với mong muốn nâng cao nhận thức của học sinh về tiêu dùng bền vững, thay đổi thái độ, dịch chuyển hành vi của học sinh, nâng cao chất lượng cuộc sống từ những hành động hàng ngày và thúc đẩy học sinh thực hiện các hành vi tiêu dùng bền vững trong cuộc sống đồng thời khuyến khích những người khác cùng tham gia.

\section{Phương pháp nghiên cứu}

\subsection{Phạm vi nghiên cúu}

Tiến hành các lớp tập huấn nâng cao nhận thức về tiêu dùng bền vững cho các em học sinh tại các trường THPT khu vực nội thành $\mathrm{TP}$. HCM.

Vị trí các trường THPT khu vực nội thành TP. HCM được thể hiện dưới bản đồ hình 1 .

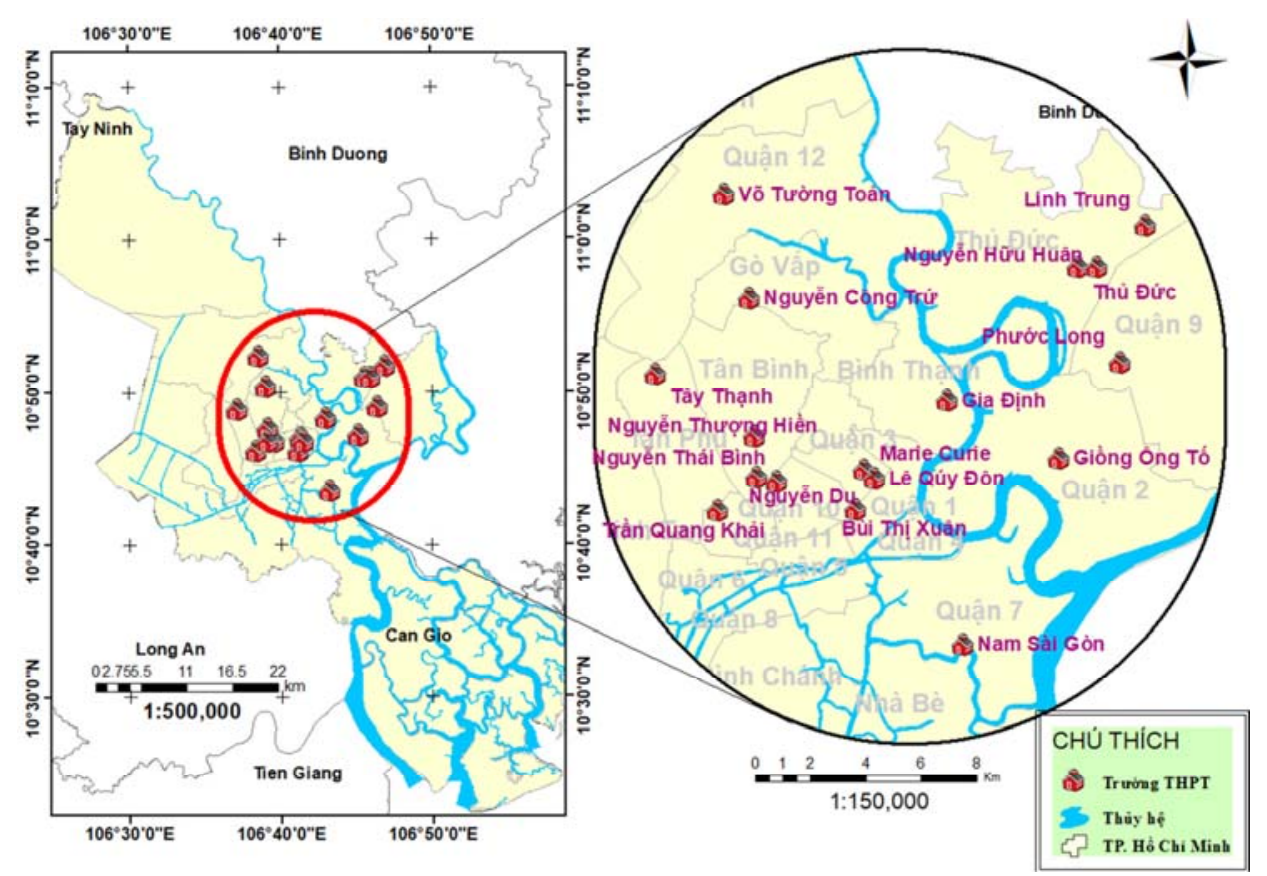

Hình 1. Bản đồ khảo sát các trường THPT khu vục nội thành TP. HCM 


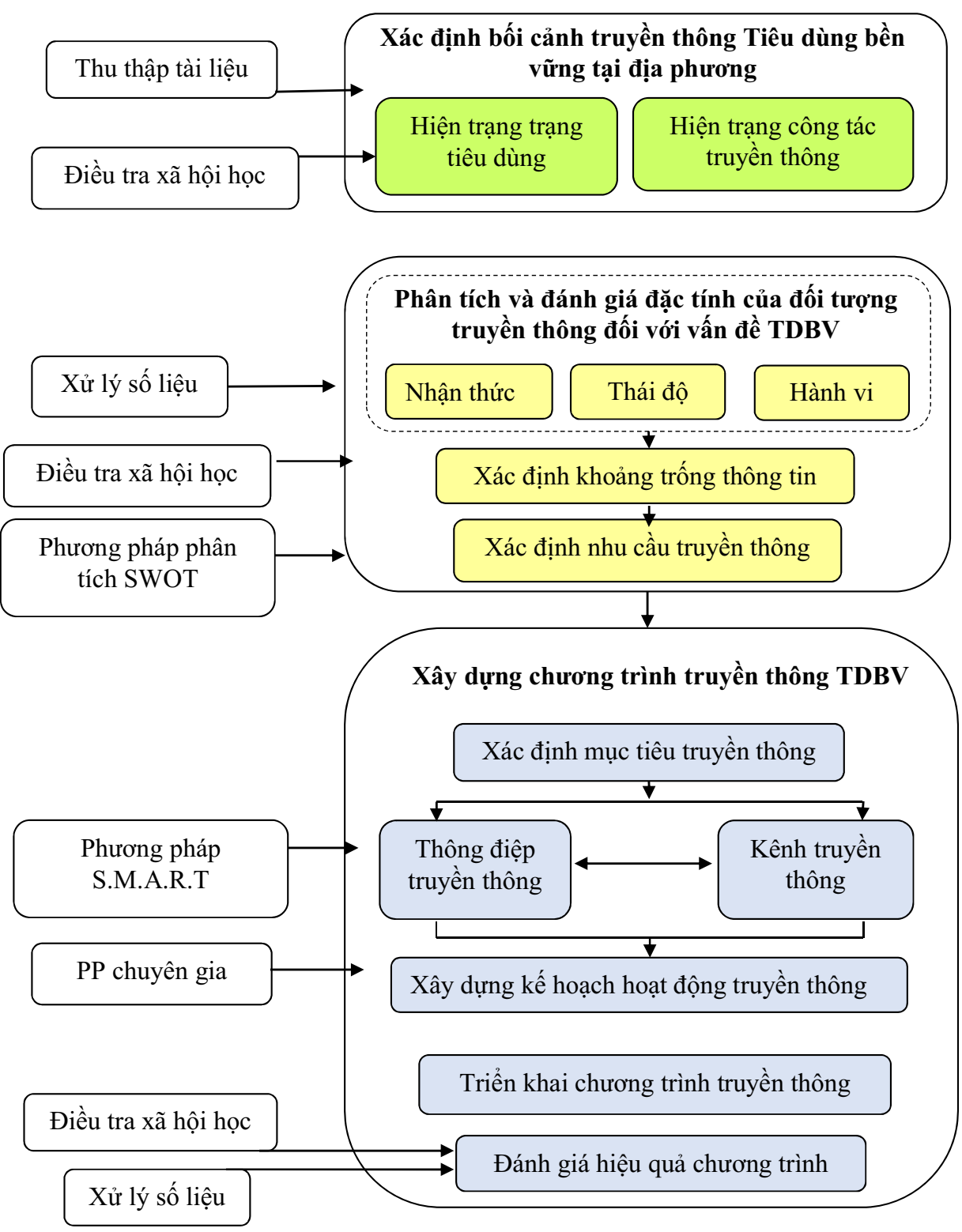

Hình 2. Khung định hướng nghiên cứu

\subsection{Phưong pháp nghiên cứu}

\subsubsection{Phưong pháp điều tra xã hội học}

Phương pháp điều tra xã hội học được thực hiện thông qua phiếu khảo sát thăm dò tham vấn ý kiến học sinh tại các trường trung học phổ thông khu vực nội thành thành phố Hồ Chí Minh.

Việc khảo sát trước và sau chương trình được thực hiện thông qua bộ câu hỏi trắc nghiệm với nội dung theo mô hình KAP (Kiến thức, nhận thức, thái độ và hành vi). Câu hỏi thiết kế được vận dụng linh hoạt để phù hợp với nội dung hỏi và với phương pháp thống kê, bao gồm câu hỏi đóng một lựa chọn, câu hỏi đóng nhiều lựa chọn, câu hỏi mở, câu hỏi nửa đóng nửa mở, câu hỏi phân đôi, câu hỏi nhiều lựa chọn và câu hỏi thang bậc [10]. Nội dung câu hỏi xoay quanh các vấn đề về tiêu dùng bền vững

Chương trình truyền thông được tiến hành tại các trường THPT Gia Định, THPT Bùi Thị Xuân, THPT Marie Curie, THPT Giồng Ông Tố, THPT Tân Bình và THPT Thủ Đức. Nhằm đảm bảo tính khách quan và tăng độ tin cậy của nghiên cứu, đề tài đã tiến hành khảo sát về các khía cạnh kiến thức, nhận thức, thái độ và hành vi của các em học sinh tham gia ở cả trước và 
sau chương trình, tổng số phiếu thu nhận được là 266 phiếu khảo sát trước chương trình và 266 phiếu khảo sát sau chương trình.

\subsubsection{Phương pháp xư lý số liệu}

Trong nghiên cứu, phần mềm Excel sẽ được áp dụng để xử lý kết quả điều tra, khảo sát. Kết quả điều tra sẽ được thống kê phục vụ đánh giá kiến thức, nhận thức, thái độ, hành vi tiêu dùng bền vững của đối tượng sinh viên trước và sau chương trình.

Để thuận tiện trong quá trình xử lý cũng như phục vụ cho việc đánh giá kiến thức, nhận thức, thái độ, hành vi, đề tài sẽ tiến hành chuẩn hóa (cho điểm) cho mỗi vấn đề trọng tâm. Mỗi câu hỏi có một đặc trưng đáp án đúng, sai khác nhau, dựa vào câu trả lời của mỗi học sinh ta có thể xác định và phân biệt được kiến thức, nhận thức, thái độ và hành vi của học sinh trước và sau chương trình.

\subsubsection{Phưong pháp tập huấn}

Đề tài đã áp dụng các phương pháp giảng dạy chủ động lấy người học làm trọng tâm để thực hiện chương trình tập huấn bao gồm: Phương pháp thuyết giảng; phương pháp quan sát; phương pháp học dựa trên tình huống, học dựa trên vấn đề; phương pháp sơ đồ tư duy; phương pháp sử dụng phim, tư liệu; phương pháp trò chơi; phương pháp học tập theo nhóm; phương pháp động não, câu đố, truy vấn; phương pháp sử dụng các công trình nghiên cứu.

\section{Kết quả nghiên cứu}

\subsection{Hiệu quả chuơng trình truyền thông}

Sau khi kết thúc chương trình tập huấn về Tiêu dùng bền vững, các em học sinh sẽ thực hiện phiếu khảo sát sau chương trình. Việc đánh giá này là cơ sở để điều chỉnh, cải tiến nội dung cũng như cách thức triển khai chương trình, thêm vào đó để đánh giá được mức khả thi của sự lan tỏa chương trình đến đối tượng tham gia. Hầu hết các tiêu chí đánh giá hiệu quả chương trình truyền thông như: nội dung, trình bày, tính hữu ích, công cụ thực hiện, thực hiện mục tiêu, công tác tổ chức và quản lý của chương trình đều được các em đánh giá cao (4,37/5 điểm).

Nhìn chung, dựa vào kết quả đánh giá nội dung, trình bày và tính hữu ích, công cụ thực hiện, việc thực hiện mục tiêu và công tác quản lý, chương trình đã đạt được những mục tiêu đề ra ban đầu là nâng cao nhận thức của học sinh về tiêu dùng bền vững, thay đổi thái độ, hành vi từ những hành động hàng ngày và thúc đẩy học sinh thực hiện các hành vi tiêu dùng bền vững trong cuộc sống đồng thời khuyến khích những người khác (bạn bè, gia đình, người thân) cùng tham gia.. Ngoài ra những nhận xét của Ban Giám hiệu các trường trung học phổ thông và chia sẻ của các em học sinh trong phạm vi chương trình đã hình thành nên bức tranh đa sắc về những hiệu quả mà chương trình mang lại.

\subsection{Kiến thức của học sinh trung học phổ thông trước và sau chuoong trình}

Sự thay đổi kiến thức của học sinh sau chương trình là một trong những yếu tố quan trọng để đánh giá hiệu quả của chương trình truyền thông, do đó, kiến thức của học sinh về tiêu dùng bền vững được khảo sát trước và sau khóa tập huấn. Kiến thức của học sinh được đánh giá thông qua phiếu khảo sát, sau đó chuẩn hóa và phân chia thành 3 mức độ: hiểu rõ, tương đối hiểu, chưa hiểu.

Các tiêu chí đánh giá kiến thức của học sinh bao gồm: thế nào là tiêu dùng bền vững, các công cụ của tiêu dùng bền vững, các nghịch lý trong tiêu dùng và dấu chân sinh thái. Kết quả khảo sát trước và sau chương trình được thể hiện trong hình 3 .

Kết quả cho thấy đã có sự thay đổi rõ rệt giữa kiến thức của các em học sinh trung học phổ thông về tiêu dùng bền vững trước và sau chương trình. Dựa trên kết quả phân tích từng tiêu chí đánh giá kiến thức của học sinh được đề cập ở trên, trước chương trình truyền thông, có đến 74,81\% học sinh có kiến thức chưa tốt về tiêu dùng bền vững, tuy nhiên, sau chương trình tỷ lệ này đã có sự dịch chuyển, cụ thể mức độ kiến thức đạt mức tốt chiếm 87,97\%. Phương pháp tổ chức lớp học, nội dung và phương pháp truyền tải, là các phương thức mà chương trình lựa chọn để cung cấp kiến thức cho các em học sinh, qua kết quả khảo sát cũng như chia sẻ, các 
em học sinh đã nhận định chính những yếu tố này góp phần giúp các em dễ dàng tiếp nhận, hiểu rõ những kiến thức mới trong nội dung chương trình, các hoạt động thảo luận nhóm, các

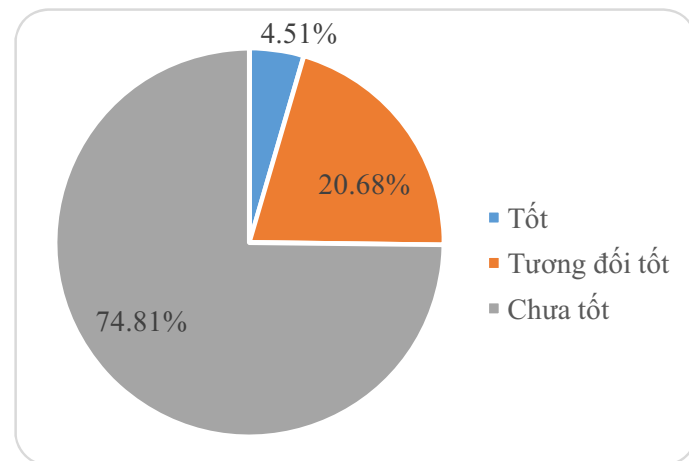

(a) Trước chương trình trò chơi được áp dụng trong các chương trình truyền thông là những yếu tố tiềm năng thay đổi hành vi và nhìn nhận sâu sắc hơn về các vấn đề toàn cầu [6].

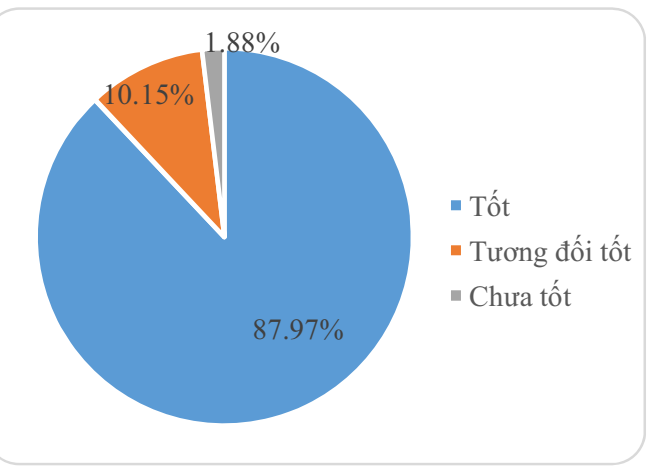

(b) Sau chuoong trinh

Hình 3. Sự thay đổi chung về kiến thức của học sinh trung học phổ thông

\subsection{Nhận thức của học sinh trung học phổ}

\section{thông trước và sau chuơng trình}

Nhận thức là hành động hay quá trình tiếp thu kiến thức và những am hiểu về một vấn đề thông qua suy nghĩ, kinh nghiệm và giác quan. Sự thay đổi nhận thức của các em sau chương trình cũng là một cấu phần quan trọng trong việc đánh giá hiệu quả chương trình truyền thông, trong khuôn khổ chương trình, đề tài đã tiến hành đánh giá sự thay đổi nhận thức của các em học sinh trước và sau chương trình.

Để tìm hiểu sự thay đổi về nhận thức của học sinh về vấn đề tiêu dùng bền vững, nghiên cứu đã tiến hành khảo sát học sinh về những nhận định liên quan đến vai trò của tiêu dùng bền vững, các yếu tố ảnh hưởng đến hành vi tiêu dùng. Kết quả đánh giá nhận thức của học sinh về tiêu dùng bền vững trước và sau chương trình được thể hiện tại hình 4.

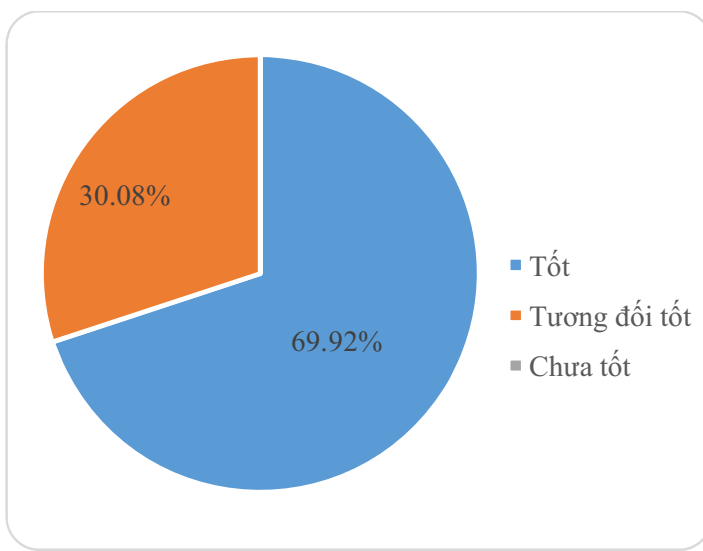

(a) Truóc chuoong trình

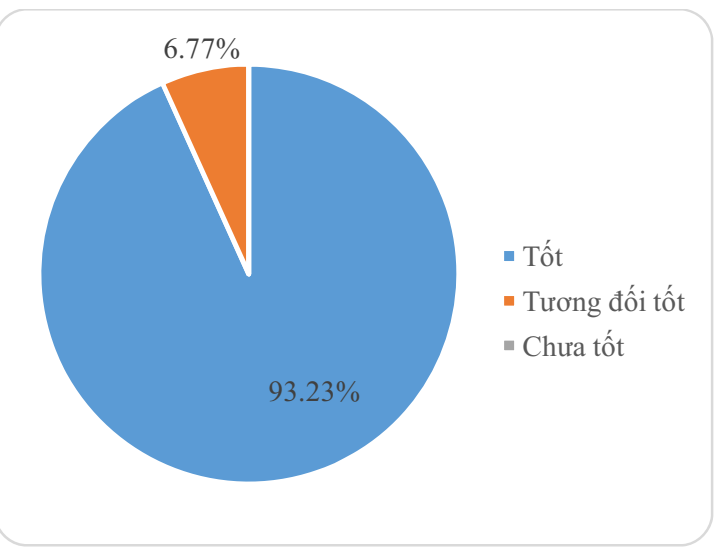

(b) Sau chuoong trình

Hình 4. Sụ thay đổi chung về nhận thức của học sinh trung học phổ thông

Kết quả cho thấy sự thay đổi nhận thức về tiêu dùng bền vững của cá em học sinh trước và sau chương trình. Trước chương trình, nhận thức của các em học sinh ở tốt chiếm 69,92\%, tương đối tốt là 30,08\%. Nhìn chung nhận thức của các em tương đối tốt do hiện nay các trường trung học phổ thông đã phát động những chương trình truyền thông như chương trình $3 \mathrm{~T}$ trong trường 


\section{BÀI BÁO KHOA HỌC}

học, phân loại rác tại nguồn, chiến dịch "xây dựng trường học xanh" và việc lồng ghép giáo dục ý thức bảo vệ môi trường cho học sinh vào các môn học đã dần hình thành được nhận thức cho các em về bảo vệ môi trường. Kết quả sau chương trình cho thấy, nhận thức của học sinh về tiêu dùng bền vững có sự thay đổi, cụ thể là nhận thức của các em ở mức độ tốt chiếm $93,23 \%$, tương đối tốt chiếm $6,77 \%$. Có thể thấy từ những kiến thức đã được cung cấp trong chương trình, các em học sinh đã có nhận thức tốt hơn về tiêu dùng bền vững và nhận thấy được rằng việc tiêu dùng của các em cũng là tác nhân gây ảnh hưởng đến môi trường.

\subsection{Thái độ của học sinh trung học phổ} thông trước và sau chuơng trình

Thái độ là nhóm yếu tố đóng góp vào định hướng giá trị sản phẩm và khả năng tiêu thụ sản phẩm, bao gồm đạo đức văn hóa, chuẩn mực xã hội, nhận thức... nó có thể định hướng tiêu dùng cá nhân cũng như ảnh hưởng đến xã hội một cách sâu sắc [2].

Từ việc phân tích những thành phần của thái độ như việc mong muốn thực hiện tiêu dùng bền

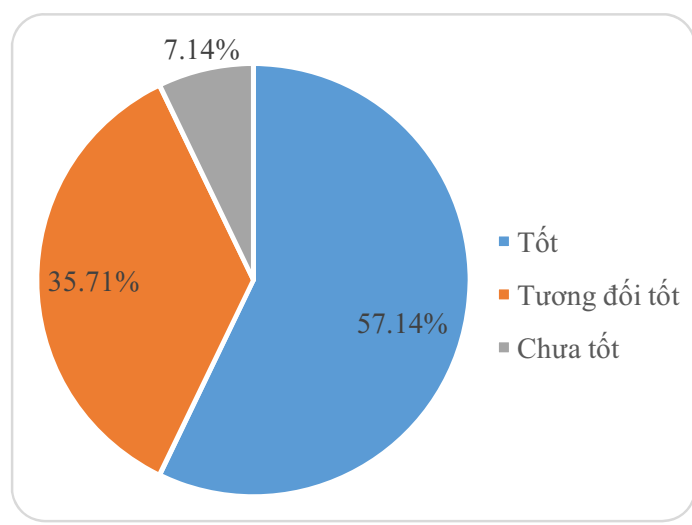

(a) Truoóc chuoong trình vững, dự định chia sẻ những kiến thức về tiêu dùng bền vững với những người xung quanh, kết quả đánh giá thái độ của học sinh trước và sau chương trình được tổng hợp trong hình 5.

Dũ liệu trên biểu đồ thể hiện trước chương trình, thái độ của học sinh vẫn chưa thật sự tốt, tỷ lệ tốt chiếm $57,14 \%$, tương đối tốt $35,71 \%$, $7,14 \%$ họ sinh ơ mức chưa tốt. Sau chương trình, có thể thấy các em đã có thái độ tốt hơn, chương trình đã thay đổi được thái độ tốt từ $57,14 \%$ lên đến $93,98 \%$. Kết quả cho thấy rằng sau khi tiếp nhận được kiến thức, thái độ của học sinh được thay đổi rõ rệt. Các em đã có dự định chia sẻ kiến thức, hành động tiêu dùng với mọi người xung quanh bằng nhiều cách khác nhau như truyền miệng, sử dụng mạng xã hội. Các kết quả thu được ở đây chỉ ra rằng việc tham gia vào hoạt động được hướng dẫn của chương trình giáo dục liên quan đến các vấn đề tiêu dùng và môi trường đã cải thiện thái độ và kiến thức của học sinh. Những kết quả này phù hợp với kết quả của một số nghiên cứu trong đó thái độ của học sinh tăng lên sau khi tham gia các chương trình lối sống sinh thái, dịch chuyển hành vi $[5,7,9]$.

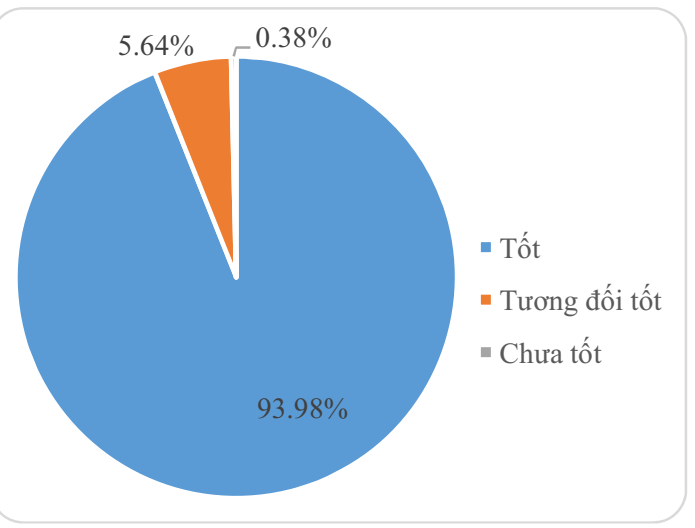

(b) Sau chuoong trìn

Hình 5. Sụ thay đổi chung về thái độ của học sinh trung học phổ thông

3.5. Hành vi của học sinh trung học phổ thông trước và sau chương trình

Nhận thức, thái độ và các chuẩn mực xã hội là nguyên nhân chính ảnh hưởng đến hành vi tiêu dùng. Mức độ dịch chuyển hành vi tiêu dùng sang tiêu dùng bền vững của học sinh được đánh giá dựa vào các hành vi tiêu dùng của các em thuộc 5 lĩnh vực: nhà ở - năng lượng; phương tiện; hàng tiêu dùng - mua sắm; tiêu dùng thực phẩm; thời gian rảnh trước và sau chương trình. Các hành vi sẽ được các em học sinh lựa chọn với ba mức độ: tôi thường xuyên làm, tôi thỉnh 
thoảng làm và tôi không làm.

Kết quả đánh giá hành vi của học sinh về tiêu dùng bền vững trước và sau chương trình được thể hiện trong hình 6 .

Dữ liệu phân tích hành vi trước và sau chương trình cho thấy kết quả khảo sát trước chương trình hành vi của các em học sinh ở mức tốt chiếm $48,87 \%$, tương đối tốt chiếm 30,83\%, chưa tốt $20,30 \%$, có thể thấy rằng các em đã có những hành vi tương đối tốt trong cuộc sống hằng ngày.

Sau chương trình, hành vi tiêu dùng của các em học sinh đã có những bước chuyển dịch rõ nét, cụ thể sau chương trình, $85,72 \%$ các em học sinh sẽ thường xuyên thực hiện các hành vi tiêu dùng thân thiện trong cuộc sống hằng ngày, $11,65 \%$ sẽ thỉnh thoảng làm và $2,67 \%$ học sinh sẽ dự định làm. Đa số những hành vi tiêu dùng bền vững về các lĩnh vực trong cuộc sống hằng ngày được đề tài đưa ra đều được các em lựa chọn sẽ trở thành thói quen tiêu dùng. Sau chương trình thái độ về tiêu dùng bền vững của học sinh đã có sự thay đổi rõ rệt vì thế sẽ tác động tích cực đến hành vi tiêu dùng của học sinh [2]. Ngoài thái độ thì nhận thức cũng là một yếu tố có liên quan mạnh mẽ đến ý định thực hiện hành vi [4], 93,23\% học sinh sau khi tham gia chương trình có nhận thức khá tốt về vấn đề tiêu dùng bền vững chính vì thế hành vi của học sinh cũng được dịch chuyển thông qua yếu tố này.

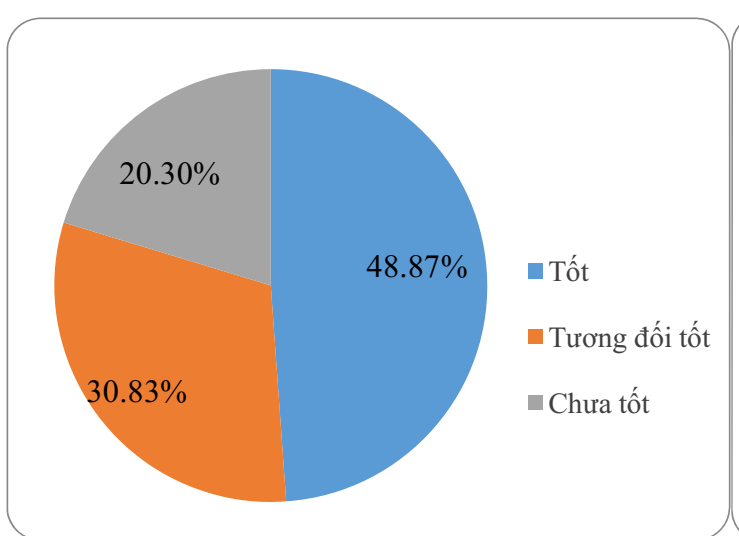

(a) Trước chuoong trình

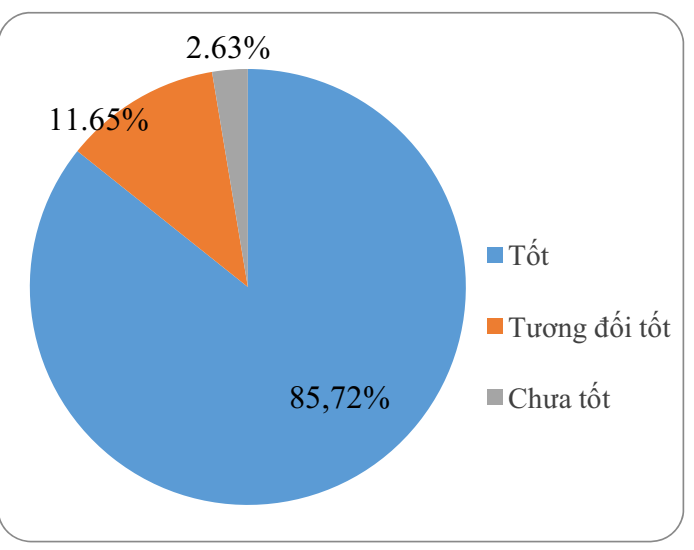

(b) Sau chioong trinh

Hình 6. Sụ thay đổi chung về hành vi của học sinh trung học phổ thông

\section{Kết luận}

Từ khảo sát trước và sau chương trình truyền thông, bằng phương pháp thu thập và xử lý số liệu, kết quả cho thấy có sự thay đổi rõ rệt kiến thức, nhận thức, thái độ, hành vi về tiêu dùng bền vững của học sinh trung học phổ thông khu vực nội thành thành phố Hồ Chí Minh. Nội dung, hình thức thực hiện, tính hữu ích, công tác tổ chức cũng như các sản phẩm của chương trình đã gây được ấn tượng tốt trong giáo viên và học sinh, bên cạnh đó là sự thay đổi rõ rệt về kiến thức, nhận thức, thái độ và hành vi của học sinh về tiêu dùng bền vững trước và sau chương trình. Kết quả khảo sát sau chương trình cho thấy kiến thức học sinh đạt mức tốt là $87,97 \%$, nhận thức hầu hết các em học sinh về tiêu dùng bền vững đều khá tốt $(93,23 \%), 93,98 \%$ học sinh có thái độ tích cực qua việc mong muốn tiêu dùng bền vững và sẽ chia sẻ kiến thức tiêu dùng bền vững với mọi người, $85,71 \%$ học sinh có những biểu hiện dịch chuyển hành vi tiêu dùng theo hướng tiêu dùng bền vững qua việc các em lựa chọn những hành vi tiêu dùng bền vững về các lĩnh vực trong cuộc sống hằng ngày được nghiên cứu đưa ra trong khảo sát sẽ trở thành thói quen tiêu dùng hằng ngày của mình. Kết quả nghiên cứu này phù hợp với nghiên cứu của Aymeric Parant [1], cho thấy rằng việc thực hiện chương trình truyền thông có thể hữu ích để nâng cao nhận thức của học sinh trung học phổ thông về tiêu dùng bền vững. 


\section{BÀI BÁO KHOA HỌC}

\section{Tài liệu tham khảo}

1. Parant, A., Pascual, A., Jugel, M., Kerroume, M., Felonneau, M.L., Guéguen, N., (2017), Raising Students Awareness to Climate Change: An Illustration With Binding Communication. Environment and Behavior, 49 (3), 1-15.

2. Chan, R.Y.K., Lau, L.B.Y., (2001), Explaining Green Purchasing Behavior : A CrossCultural Study on American and Chinese Consumers. Journal of International Consumer Marketing, 14, 940 .

3. Jabes, D., Sciangula, C., Russo, V., Re, A., (2012), Sustainable native: Sustainable consumption behavior among young Italians. 5th International Conference on Multidisciplinary Perspectives on Child and Teen Consumption 2012, 144-152.

4. Dahab, D.J., Gentry, J.W., Su, W., (1995), New way to reach non - recyclers: an extension of the model of reasoned action recycling behaviors. in Kades, F.R. and Sujan, M. (Eds). Advances in Consumer Research, Association Consumer Research, Provo, UT, pp. 251-256.

5. Johnson, B., Manoli, C.C., (2011), The 2-MEV scale in the United States: A measure of children's environmental attitudes based on the theory of ecological attitude. The Journal of Environmental Education, 42 (2), 84-97.

6. Flora, J.A., Saphir, M., Lappé, M. et al, (2014), Evaluation of a national high school entertainment education program: The Alliance for Climate Education. Springer Netherlands, 127: 419.

7. Genc, M., Genc, T., Rasgele, P.G., (2017), Effects of nature-based environmental education on the attitude of 7 th grade students towards the environment and living organisms and affective tendency. International Research in Geographical and Environmental Education.

8. Nkanikpo, I., George, E.S., (2014), Socio-Economic and Demographic Determinants of Green Consumption. International Journal of Managerial Studies and Research (IJMSR) 2 (9), 47 - 56.

9. Sellmann, D., Bogner, F., (2013), Effects of a 1-day environmental education intervention on environmental attitudes and connectedness with nature. European Journal of Psychology of Education, 28, 1077-1086.

10. Stokking, K., Van Aert, L., Meijberg, W., and Kaskens, A., (1999), Evaluating environmental education. IUCN Publications Services Unit, 219.

11. Thủ tướng Chính phủ (2019), Chỉ thị số 19/CT-TTg về các giải pháp thúc đẩy tăng trưởng và phát triển bền vững Vùng kinh tế trọng điểm phía Nam.

12. Thủ tướng Chính phủ (2012), Quyết định số 1393/QĐ-TTg phê duyệt Chiến lược quốc gia về tăng trưởng xanh giai đoạn 2011-2020 và tầm nhìn đến 2050 .

13. Trung tâm Sản xuất sạch hơn Việt Nam (VNCPC) (2012), Get Green Viet nam.

14. UNEP (2012), Sustainable for Porvety Alleviation.

15. UNEP (2016), A framework for Shaping Sustainable Lifestyles: Determinants and Strategies.

16. UNEP/UNESCP/META (2007), YouthXchange: toward sustainable lifestyle; training kit on responsible consumption - The giude, 2 nd edition.

17. UNEP (2010), Here and now Sustainable Consumption Education. 


\title{
RAISING AWARENESS CAMPAIGN ABOUT SUSTAINABLE CON- SUMPTION FOR HIGH SCHOOL STUDENTS IN THE INNER AREA OF HO CHI MINH CITY
}

\author{
Dang Thi Thanh Le', Nguyen Ky Phung², To Thi Hien', Nguyen Thi Thu Hien², \\ Huynh Ngoc Thuy An ${ }^{3}$, Vo Van Anh ${ }^{3}$ \\ ${ }^{1}$ University of Science - VNU \\ ${ }^{2}$ Institude for Computational Science and Technology \\ ${ }^{3}$ University of Natural Resources and Environment Ho Chi Minh City
}

\begin{abstract}
Raising awareness campaign about sustainable consumption for high school students was implemented at 6 high schools in the inner area of Ho Chi Minh City, the content was divided into 4 training sessions with communication topics related to basic knowledge about sustainable consumption, ecological footprint, sustainable consumption tools and sustainable consumption action in the fields of energy, vehicles, consumer goods - and purchasing. shopping, food, free time conveyed through training channels, posters, brochures, handbooks, documents. Accordingly, the communication program was organized and received positive feedback, the survey results of 266 high school students pre and post - campaign the program showed that $87.97 \%$ of students had gained knowledge. The background of sustainable consumption, awareness and attitudes of most students about sustainable consumption are quite good, 98.12\% of students want to consume sustainably and learn more knowledge. Regarding more sustainable consumption, the consumption behavior of students has made clear changes after the program, $85.72 \%$ of students will regularly implement friendly consumer behaviors in daily life.
\end{abstract}

Keywords: Sustainable consumption, communication campaigns, sustainable consumption behavior, high school students. 